3 Gold D, Bowden R, Sixbey J, Riggs R, Katon WJ, Ashley R, et al. Chronic fatigue: a prospective clinical and virologic study. JAMA 1990;264:48-53. fatigue: a prospective clinical and virologic study. JAMA 1990;264:48-53

LB, et al. Lack of evidence for infection with known human and animal $\mathrm{LB}$, et al. Lack of evidence for infection with known human and animal
retroviruses in patients with chronic fatigue syndrome. Clin Infect Dis retroviruses in patients with chronic fatigue syndrome. Clin Infect $D i$ 1994;18(suppl 1):S121-5.

5 Mawle AC, Nisenbaum R, Dobbins JG, Gary HE Jr, Stewart JA, Reyes M, et al. Seroepidemiology of chronic fatigue syndrome: a case-contro study. Clin Infect Dis 1995;21:1386-9.

6 Evans AC. Chronic brucellosis. JAMA 1934;103:665.

Isaacs R. Chronic infectious mononucleosis. Blood 1948;3:858-61.

8 Shadick NA, Phillips CB, Logigian EL, Steere AC, Kaplan RF, Berardi VP, et al. The long-term clinical outcomes of Lyme disease: a populationet al. The long-term clinical outcomes of Lyme disease: a pop

9 Ayres JG, Flint N, Smith EG, Tunnicliffe WS, Fletcher TJ, Hammond K, et al. Post-infection fatigue syndrome following Q fever. OJM 1998;91:105-

10 Harley D, Bossingham D, Purdie DM, Pandeya N, Sleigh AC. Ross River virus disease in tropical Queensland: evolution of rheumatic manifestations in an inception cohort followed for six months. Med J Aus 2002;177:352-5

11 Hotopf M, Noah N, Wessely S. Chronic fatigue and psychiatric morbidity following viral meningitis: a controlled study. I Neurol Neurosurg Psychiatry 1996;60:495-503.

12 Wessely S, Chalder T, Hirsch S, Pawlikowska T, Wallace P, Wright D. Postinfectious fatigue: prospective cohort study in primary care. Lancet Postinfectious fatigu

13 Wittchen HU, Robins LN, Cottler LB, Sartorius N, Burke JD, Regier D Participants in the multicentre WHO/ADAMHA field trials, 1991: crosscultural feasibility, reliability and sources of variance of the composite international diagnostic interview (CIDI). Br J Psychiatry 1991;159:64553.

14 Hadzi-Pavlovic D, Hickie IB, Wilson AJ, Davenport TA, Lloyd AR. Screening for prolonged fatigue syndromes: validation of the SOFA scale. Soc Psychiatry Psychiatr Epidemiol 2000;35:471-9.

15 Von Korff M, Ustun TB, Ormel J, Kaplan I, Simon GE. Self-report disability in an international primary care study of psychological illness. J Clin Epidemiol 1996;49:297-303.
16 Fukuda K, Straus SE, Hickie I, Sharpe MC, Dobbins JG, Komaroff A. The chronic fatigue syndrome: a comprehensive approach to its definition and study Ann Intern Med 1994:121:953-9.

17 Robertson P, Beynon S, Whybin R, Brennan C, Vollmer-Conna U, Hickie I, et al. Measurement of EBV-IgG anti-VCA avidity aids the early and reliable diagnosis of primary EBV infection. J Med Virol 2003;70:617-23.

18 Worswick D, Marmion BP. Antibody responses in acute and chronic $Q$ fever and in subjects vaccinated against $\mathrm{Q}$ fever. $J$ Med Microbiol $1985 ; 19: 281-96$

19 Rickinson A, Kieff E. Epstein-Barr virus. In: Knipe D, Howley P, eds. Field's virology. Philadelphia, PA: Lippincott, Williams \& Wilkins, 2001:2575698

20 Maurin M, Raoult D. O fever. Clin Microbiol Rev 1999:12:518-53.

21 Harley D, Sleigh A, Ritchie S. Ross River virus transmission, infection and disease: a cross-disciplinary review. Clin Microbiol Rev 2001;14:909-32.

22 White PD, Thomas JM, Amess J, Grover SA, Kangro HO, Clare AW. The existence of a fatigue syndrome after glandular fever. Psychol Med 1995;25:907-16

23 White PD, Thomas JM, Amess J, Crawford DH, Grover SA, Kangro HO, et al. Incidence, risk and prognosis of acute and chronic fatigue syndromes and psychiatric disorders after glandular fever. Br J Psychiatr 1998;173:475-81.

24 White PD, Thomas JM, Kangro HO, Bruce-Jones WD, Amess J, Crawford $\mathrm{DH}$, et al. Predictions and associations of fatigue syndromes and mood disorders that occur after infectious mononucleosis. Lancet 2001:358:1946-54.

25 Buchwald DS, Rea T, Katon W, Russo JE, Ashley RL. Acute infectious mononucleosis: characteristics of patients who report failure to recover. Am J Med 2000;109:531-7.

26 Candy B, Chalder T, Cleare AJ, Peakman A, Skowera A, Wessely S, et al. Predictors of fatigue following the onset of infectious mononucleosis Psychol Med 2003;33:847-55.

27 White PD, Thomas JM, Sullivan PF, Buchwald D. The nosology of sub-acute and chronic fatigue syndromes that follow infectious mononucleosis. Psychol Med 2004:34:499-507.

(Accepted 2 August 2006)

doi 10.1136/bmj.38933.585764.AE

\title{
Diagnostic accuracy of clinical examination for detection of non-cephalic presentation in late pregnancy: cross sectional analytic study
}

Natasha Nassar, Christine L Roberts, Carolyn A Cameron, Emily C Olive

Editorial by

Nicholson

Centre for Perinatal

Health Services

Research, School of

Public Health,

University of

Sydney NSW 2006,

Australia

Natasha Nassar

research associate

Christine L Roberts

research director

Carolyn A

Cameron

research associate

Emily C Olive

research fellow in

obstetrics

Correspondence to

N Nassar

natashan@

ichr.uwa.edu.au

BMJ 2006;333:578-80

\section{Abstract}

Objective To examine the diagnostic accuracy of clinical examination to determine fetal presentation in late pregnancy.

Design Cross sectional analytic study with index test of clinical examination and reference standard of ultrasonography.

Setting Antenatal clinic in tertiary obstetric hospital in Sydney, Australia.

Participants 1633 women with a singleton pregnancy between 35 and 37 weeks' gestation attending antenatal clinics.

Intervention Fetal presentation assessed by clinical examination during routine antenatal care, followed by ultrasonography to confirm the diagnosis.

Main outcome measures Sensitivity, specificity, and positive and negative predictive values of clinical examination compared with ultrasonography.

Diagnostic rates by maternal characteristics.

Results Ultrasonography identified non-cephalic presentation in $130(8 \%)$ women, comprising 103 $(6.3 \%)$ with breech and $27(1.7 \%)$ with transverse or oblique lie. Sensitivity of clinical examination for detecting non-cephalic presentation was 70\% (95\% confidence interval $62 \%$ to $78 \%$ ) and specificity was
$95 \%$ (94\% to $96 \%)$. The positive predictive value and negative predictive value were $55 \%$ and $97 \%$, respectively.

Conclusions Clinical examination is not sensitive enough for detection and timely management of non-cephalic presentation.

\section{Introduction}

Antenatal detection of non-cephalic presentationcomprising breech presentation and transverse or oblique lie-in late pregnancy is important for timely management and clinical decision making. For breech presentation, women and their clinicians must decide whether to try external cephalic version to increase the likelihood of vaginal birth or plan a caesarean section, with optimal gestation being 37 and 39 weeks, respectively. ${ }^{1}$ Diagnosis of non-cephalic presentation after the onset of labour is associated with increased maternal and infant morbidity and mortality. ${ }^{2}$

Fetal presentation is generally assessed by palpating the abdomen (clinical examination), though we do

This article was posted on bmj.com on 4 August 2006: http://bmi.com/ cgi/doi/10.1136/bmj.38919.681563.4F 
Sensitivity and specificity (as \%) of clinical examination for detecting fetal presentation

\begin{tabular}{|c|c|c|c|c|}
\hline \multirow[b]{2}{*}{ Characteristic } & \multicolumn{2}{|c|}{ Non-cephalic, correctly diagnosed } & \multicolumn{2}{|c|}{ Cephalic, correctly diagnosed } \\
\hline & No of cases & Sensitivity $(95 \% \mathrm{CI})$ & No of cases & Specificity $(95 \% \mathrm{CI})$ \\
\hline Overall & $91 / 130$ & 70 (62 to 78$)$ & $1429 / 1503$ & 95 (94 to 96$)$ \\
\hline \multicolumn{5}{|l|}{ Maternal age (years): } \\
\hline$<35$ & $55 / 84$ & 65 (64 to 66) & $1100 / 1158$ & 95 (94 to 96$)$ \\
\hline$\geq 35$ & $34 / 44$ & 77 (75 to 79$)$ & $319 / 336$ & 95 (94 to 96$)$ \\
\hline \multicolumn{5}{|l|}{ Gestational age (weeks): } \\
\hline $34-35$ & $32 / 41$ & 78 (76 to 80 ) & $316 / 343$ & 92 (91 to 93 ) \\
\hline 36 & $29 / 44$ & 66 (64 to 68$)$ & $492 / 512$ & 96 (95 to 97$)$ \\
\hline $37-38$ & $28 / 43$ & 65 (63 to 67) & $615 / 641$ & 96 (95 to 97 ) \\
\hline \multicolumn{5}{|l|}{ Parity: } \\
\hline Nulliparous & $49 / 73$ & 67 (65 to 68) & $779 / 820$ & 95 (94 to 96$)$ \\
\hline Multiparous & $42 / 57$ & 74 (72 to 75$)$ & $643 / 677$ & 95 (94 to 96 ) \\
\hline \multicolumn{5}{|l|}{ Body mass index: } \\
\hline Thin & $9 / 13$ & 69 (62 to 76) & 109/115 & 95 (94 to 96 ) \\
\hline Normal weight & $49 / 67$ & 73 (72 to 74$)$ & $862 / 898$ & 96 (95 to 97 ) \\
\hline Overweight & 19/28 & 68 (65 to 71$)$ & $234 / 241$ & 97 (96 to 98$)$ \\
\hline Obese & $3 / 8$ & 38 (26 to 49$)$ & 139/156 & 89 (88 to 90) \\
\hline \multicolumn{5}{|l|}{ Country of birth: } \\
\hline Australia/New Zealand/Europe & $52 / 72$ & 72 (71 to 73 ) & $855 / 900$ & 95 (94 to 96 ) \\
\hline Asia & $18 / 39$ & 46 (67 to 72$)$ & $407 / 424$ & 96 (95 to 97 ) \\
\hline Other & $8 / 11$ & 69 (37 to 54) & $144 / 152$ & 95 (94 to 96$)$ \\
\hline
\end{tabular}

Numbers may not add up to totals because of missing data.

not know the accuracy of this in late pregnancy. ${ }^{3-6}$ We conducted a cross sectional analytic study to compare clinical examination with the reference standard of ultrasonography.

\section{Methods}

\section{Patients, setting, and data collection}

We carried out the study at an antenatal clinic in a tertiary obstetric hospital between September 2003 and December 2004. Women with a singleton pregnancy at 35-37 weeks' gestation were eligible. A midwife, resident, registrar, or obstetrician, all of whom were aware of the study, provided routine antenatal care. All eligible women underwent clinical examination to assess fetal presentation. Subsequently, those who consented to participate underwent ultrasonography to confirm the diagnosis. The ultrasound examination was conducted with a portable hand held machine following a standard protocol. The operators were blinded to the result of the clinical examination until after the ultrasonography.

We collected data from the antenatal record and recorded it on a standard data abstraction form. We assessed the accuracy of clinical examination in diagnosing fetal presentation by calculating sensitivity, specificity, and positive and negative predictive values.

\section{Sample size and analysis}

To determine a sensitivity of $75 \%$ (with a $95 \%$ confidence interval plus or minus $10 \%$ ) we required 100 women with a breech presentation. As $6-8 \%$ of singleton pregnancies are breech at $35-37$ weeks' gestation, ${ }^{7}$ we needed between 1250 and 1700 women to gain a sample of 100 with a breech presentation. We investigated predictive factors associated with correct diagnosis of fetal presentation using contingency tests and used sensitivity analyses to examine specific accuracy rates by maternal characteristics. $\mathrm{P}<0.05$ was considered significant and analyses were conducted with SAS version 8.2 (SAS Institute, Cary, NC).

\section{Results}

Of the 1707 eligible women approached, 65 women refused to take part because of lack of time or concern about having had too many ultrasound examinations during their pregnancy, and nine women were excluded owing to missing data. The average age of the 1633 participating women was 31 years (SD 5.4); 55\% were nulliparous; $31 \%$ were overweight or obese; and $61 \%$ were white. Over 60 care providers participated, with $55 \%$ of examinations performed by residents or registrars, $28 \%$ by midwives, and $17 \%$ by obstetricians.

Ultrasonography identified non-cephalic presentation in 130 (8\%) women, comprising 103 (6.3\%) with breech and $27(1.7 \%)$ with transverse or oblique lie. The sensitivity of clinical examination for identifying non-cephalic presentation was $70 \%$ and specificity was 95\% (table). A similar rate of sensitivity was found for breech presentation $(70 \%, 61 \%$ to $78 \%)$. The positive and negative predictive values were $55 \%$ and $97 \%$, respectively.

The sensitivity of clinical examination for determining non-cephalic presentation was not associated with any particular maternal characteristics, but there was a trend of increasing sensitivity for women with a previous pregnancy (multiparous) and lower body mass index (table). The proportion of women in whom cephalic presentation was correctly diagnosed (specificity) was significantly greater with increasing gestational age and decreasing body mass index $(\mathrm{P}<0.05)$ (table).

\section{Discussion}

In this large study in a general maternity population we found that clinical examination was, generally, not sensitive enough to accurately diagnose fetal presentation in late pregnancy. Although clinical examination increased the probability of diagnosis from $8 \%$ (prior probability or prevalence) to $55 \%$ (posterior probability or positive predictive value), ${ }^{8}$ only $70 \%$ of 
non-cephalic presentations were detected. If we apply our findings to a general maternity population of 1000 women, clinical examination would identify 101 women as having a non-cephalic presentation but in only 56 would this be correct; and 24 women with non-cephalic presentation would be missed altogether.

\section{Strengths and limitations of the study}

We included a large unselected sample and used appropriate timing of the clinical examination relevant for management of non-cephalic presentation in late pregnancy. Previous reports of the sensitivity of clinical examination for detecting non-cephalic presentation have ranged from $28-88 \%$. These studies were small, underpowered, and included selected high risk pregnancies and low gestational ages (range 20-42 weeks). ${ }^{3-6}$ Our observed prevalence of non-cephalic presentation was consistent with rates found in longitudinal studies of fetal presentation, ${ }^{9}$ suggesting that our findings may be applied in other obstetric settings.

We did not collect information on individual clinicians and were unable to ascertain whether particular individuals may have biased results. As all examiners were aware of the study and assessments were recorded and verified, we assumed that assessors would be vigilant. Nevertheless, it is possible that some clinicians may not have been as attentive because diagnoses were going to be checked with ultrasonography.

\section{Room for improvement}

Introduction of routine ultrasonography to assess fetal presentation in late pregnancy would improve diagnostic accuracy. However, costs, resource availability, and feasibility need to be considered, as well as the potential deskilling of care providers in performing clinical examination. A cost effectiveness analysis would be necessary before implementation and change in clinical obstetric practice. However, lower rates of accuracy found among overweight or obese women suggest that formal ultrasonography in late pregnancy for these women is required.

Clinical examination to assess fetal presentation is a relatively simple procedure and, with ongoing diligence and regular audit and feedback, accuracy may be increased. Variability in accuracy rates by examiner and level of experience also suggest there is room for improvement by all pregnancy care providers. ${ }^{3} 510$

\section{What is already known on this topic}

There is limited information about the accuracy of clinical examination for detection of fetal presentation in late pregnancy

\section{What this study adds}

Compared with ultrasonography, the sensitivity of clinical examination is inadequate for detection and timely management of non-cephalic presentation

We thank the staff and the women at Royal Prince Alfred Women and Babies Hospital who participated in the study for their time and cooperation. We particularly thank Hala Phipps, Sarah Charlton, and Julie Bedford for recruiting women and performing the ultrasound examinations.

Contributors: See bmj.com.

Funding: Australian National Health and Medical Research Council (NHMRC) project grant (211051). NN was funded by an Australian NHMRC Public Health Postgraduate Research Scholarship. CLR was funded by an Australian NHMRC Public Health Practitioner Fellowship.

Competing interests: None declared.

Ethical approval: Approved by the Central Sydney Area Health Service Research Ethics Committee (Protocol number: X030185).

1 Hofmeyr GJ, Kulier R. External cephalic version for breech presentation at term. Cochrane Database Syst Rev 2000;(2):CD000083.

Waterstone $\mathrm{M}$, Bewley S, Wolfe $C$. Incidence and predictors of severe obstetric morbidity: case-control study BMJ 2001:322:1089-93.

3 Watson WJ, Welter S, Day D. Antepartum identification of breech presentation.J Reprod Med 2004;49:294-6.

tation. J Reprod Med 2004;49:294-6.
4 Thorp JM Jr, Jenkins T, Watson W. Utility of Leopold maneuvers in Thorp JM Jr, Jenkins T, Watson W. Utility of Leopold mane
screening for malpresentation. Obstet Gynecol 1991;78:394-6.

McFarlin BL, Engstrom JL, Sampson MB, Cattledge F. Concurrent validity of Leopold's maneuvers in determining fetal presentation and position. J Nurse Midwifery 1985;30:280-4.

6 Lydon-Rochelle M, Albers L, Gorwoda J, Craig E, Qualls C. Accuracy of Leopold maneuvers in screening for malpresentation: a prospective study. Birth 1993;20:132-5

7 Roberts CL, Nassar N, Raynes-Greenow CH, Peat B. Update on the management of term breech deliveries in NSW, Australia. Aust N Z J Obstet Gynaecol 2003:43:173.

8 Altman DG, Bland JM. Diagnostic tests 2: predictive values. BMJ 1994;309:102

9 Scheer K, Nubar J. Variation of fetal presentation with gestational age. $A m$ J Obstet Gynecol 1976;125:269-70.

10 Nassar N. Breech presentation: facilitating informed decision-making [dissertation]. Sydney, NSW: University of Sydney, 2005.

(Accepted 29 June 2006)

doi 10.1136/bmj.38919.681563.4F

\section{A testing time}

"It won't take long, Will."

An old friend was looking for subjects for his research project. "Just blow out as forcefully and as long as you can."

I blew out hard and squeezed the air from my lungs into the spirometer. When I passed the machine to my friend, however, he looked at it with a puzzled expression: "Less than $80 \%$ predicted for a man of your height and weight. That's strange-well, we see this sometimes."

On my cycle home, I wondered if I had lagged behind at school cross-country races because of my poor lung volumes. Perhaps those vague chest pains were the start of a horrible respiratory disease? Two days later there was an explanation. The spirometer was incorrectly calibrated, and on repeat testing my lung capacity was normal. A relief for me, and two days of worry were over.

Unexpected and unexplained results can lead to anxiety. Clinicians and researchers need to tell their patients and subjects that tests may not be benign. At the very least they can lead to sleepless nights in a colleague with an active imagination.

William Whiteley specialist registrar in medical neurology, Department of Clinical Neurosciences, Western General Hospital, Edinburgh

(wwhitele@staffmail.ed.ac.uk) 